\title{
An Intelligent Control System Design for an Evaporator based on Particle Swarm Optimization
}

\author{
Hala A. Abdel-Halim \\ Hot Laboratory and Waste \\ Management Center, AEA, Cairo, \\ Egypt. P.O 13759
}

\author{
A. A. Zaki \\ Hot Laboratory and Waste Management Center, \\ AEA, Cairo, Egypt. P.O 13759
}

\author{
Othman E. A. \\ Computers and Systems Eng. \\ Dept., Zagazig Univ., Zagazig, \\ Egypt.
}

\author{
A. A. Sakr \\ Hot Laboratory and Waste \\ Management Center, AEA, Cairo, \\ Egypt. P.O 13759
}

\author{
A. A. Abouelsoud \\ Electronics and Communications Eng. Dept., Cairo \\ Univ., Cairo, Egypt.
}

\begin{abstract}
The main contribution of this paper is aimed to design and implementation of an intelligent level controller and intelligent $2 \times 2$ decentralized PI controller and a lead compensator for the forced circulation evaporator by using PSO strategy. The most important thing to guarantee the safe operation of the forced circulation evaporator, without damaging the installed equipment, is obtaining optimal controllers for the evaporator operating pressure and the level of liquid inside the separator part. Also the percent of the concentration of the non-volatile in the solution must be effectively controlled to required limits. PSO algorithm is implemented in MATLAB and is compared to GA strategy for design and implementation of optimal controllers for the evaporator system by minimizing the summation of the characteristics of unit step response. Also computer simulation results are compared to the different two cost functions methods by analyzing the performance, stability and robustness with respect to variation of the evaporator control system.
\end{abstract}

\section{General Terms}

Process Control, Intelligent Control, Optimal Control, Particle Swarm Optimization, Genetic Algorithm.

\section{Keywords}

Particle Swarm Optimization; Genetic Algorithm; Forced Circulation Evaporator; Performance Indices.

\section{INTRODUCTION}

PID controller is most widely used controller in chemical process industries because of its simplicity, robustness and successful practical application. Recently, tuning of PI/PID controller by using intelligent optimization techniques such as PSO and GA has attracted a lot of research interests [1], [2], [3], [4] and [5]. These include intelligent optimization techniques such as particle swarm optimization [6] and [7] and Genetic Algorithm [8], [9] and [10].

Controlling of chemical processes (which are basically Multi Input Multi Output systems) is not straight forward due to the coupling and interactions between channels. To overcome this challenge, tuning of decentralized PI/PID controller by using intelligent optimization techniques such as PSO and GA [11], [12], [13], [14], [15], [16], [17], [18], [19] and [20] are used due to their less complexity, high performance and easy implementation. Genetic algorithms (GAs) belong to the larger class of evolutionary algorithms, which generate solutions to optimization problems using techniques inspired by natural evolution, such as inheritance, mutation, selection, and crossover [21]. The genetic algorithm repeatedly modifies a population of individual solutions. At each step, the genetic algorithm selects individuals from the current population to be parents and uses them to produce the children for the next generation. Over successive generations, the population "evolves" toward an optimal solution.

PSO is a robust stochastic optimization technique based on the movement and intelligence of swarms. It was developed in 1995 by James Kennedy (social-psychologist) and Russel Eberhart (electrical engineer) [22]. It is one of the strongest methods for solving optimization problems. The method is proved to be robust in solving problems featuring nonlinearity and non-differentiability, multiple optima, and high dimensionality. The advantages of the PSO are its relative simplicity and stable convergence characteristic with good computational efficiency [23]. Also PSO has advantages over GA; PSO has faster execution time than GA because it has only one operator; velocity calculation. However GA requires performing selection, crossover and mutation operations, so implementation of PSO is easier than implementation of GA [24].

In the previous work [25], we employed genetic algorithm GA to obtain the optimum parameters of an evaporator control system by using different tuning methods. The proposed method using cost functions Integral of Square Error ISE plus summation of step response parameters such; rise time $\mathrm{Tr}$, settling time $\mathrm{Ts}$, maximum overshoot $\mathrm{Mp}$ and steady state error Ess. (ISE + SRP) and (IAE+SRP) were more efficient, stable and robust compared with the ordinary tuning methods using performance indices only, such as Integral of Absolute Error (IAE), Integral of Square Error (ISE), Integral of Time Absolute Error (ITAE) and Integral of Time multiplied with Square Error (ITSE).

This paper utilizes PSO algorithm and comparing to GA strategy for design and implementation of optimal controllers for the evaporator system by minimizing the summation of the characteristics of step response. Also simulation results are compared to the different two cost functions methods.

This paper contains 7 sections beside the introduction. In section 2 the proposed objective function and the other used two objective functions groups are presented. Section 3 explains particle swarm optimization technique in details. Section 4 devoted for describing in details the used evaporation system. Applying GA and PSO to obtain the parameters of level control and to choose the parameters of 
the decoupler controller for evaporator system are illustrated in section 5. Section 7 gives the conclusion of paper.

\section{OBJECTIVE FUNCTIONS}

Performance index is a measure of a system's performance that confirms the characteristics of the system's response which are considered important [26].

The well-known integral performance indices as follow:

- Integral Absolute Error $(\operatorname{IAE})=\int_{0}^{\mathrm{t}}|\mathrm{e}(\mathrm{t})| \mathrm{dt}$

- Integral Square Error(ISE) $=\int_{0}^{t} \mathrm{e}^{2} \mathrm{dt}$

- Integral Time Absolute Error (ITAE) $=\int_{0}^{t} t|e(t)| d t$

- Integral Time Square Error (ITSE) $=\int_{0}^{t} t e^{2} d t$.

Where $t$ is the time interval and $\mathrm{e}(\mathrm{t})$ is the difference between set point and controlled variable.

Most researches take some or all of the previous integral performance indices as cost functions in optimal control design and analysis the control system performance by investigating the parameters of time response parameters. So in this paper, we propose a simple and a direct cost function that is the summation of step response parameters only as follows;

- $S P R=\omega_{0} \cdot T_{r}+\omega_{1} \cdot T_{S}+\omega_{2} \cdot M_{P}+\omega_{2} \cdot E_{S S}$

Where $T_{r}$ is Rise Time, $T_{S}$ is settling Time, $M_{P}$ is Maximum Overshoot and $E_{S S}$ is steady state error

And constants $\omega_{0}, \omega_{1}$ and $\omega_{2}$ should be selected by the designer according to the case. In our case, take these parameters equal to 1 .

This cost function is compared with two groups of cost functions;

- First group considers integral performance indices separately;

$$
\text { * IAE, *ISE, *ITAE, *ITSE }
$$

- Second group considers integral performance indices separately plus Step response parameters;

\section{*IAE+SRP， * ISE+SRP， * ITAE+SRP， *ITSE+SRP}

\section{PARTICLE SWARM OPTIMIZATION}

$\mathrm{PSO}$ as a population-based evolutionary algorithm is an optimization method based on natural behaviour of birds flocking or fish [22]. All solutions in PSO can be represented as particles in a swarm. Each particle has a position and velocity vector and each position coordinate represents a parameter value. Similar to the most optimization techniques, PSO requires a fitness evaluation function relevant to the particle's position. $\mathrm{X}_{\mathrm{PB}}$ and $\mathrm{X}_{\mathrm{GB}}$ are the personal best (Pbest) position and global best (Gbest) position of the ith particle.

Each particle is initialized with a random position and velocity. The velocity of each particle is accelerated toward the global best and its own personal best based on equation (1) [27]:

$$
\begin{aligned}
V_{i}(\text { new })= & \omega \times V_{i}(\text { old })+C_{1} \times R 1 \times\left(X_{P B}-X_{i}\right)+ \\
& C_{2} \times R 2 \times\left(X_{G B}-X_{i}\right)
\end{aligned}
$$

Here R1 and R2 are two random numbers in the range [0, 1]; $\mathrm{C}_{1}$ and $\mathrm{C}_{2}$ are the acceleration constants and $\omega$ is the inertia weight factor. The parameter $\omega$ helps the particles converge to Gbest, rather than oscillating around it.

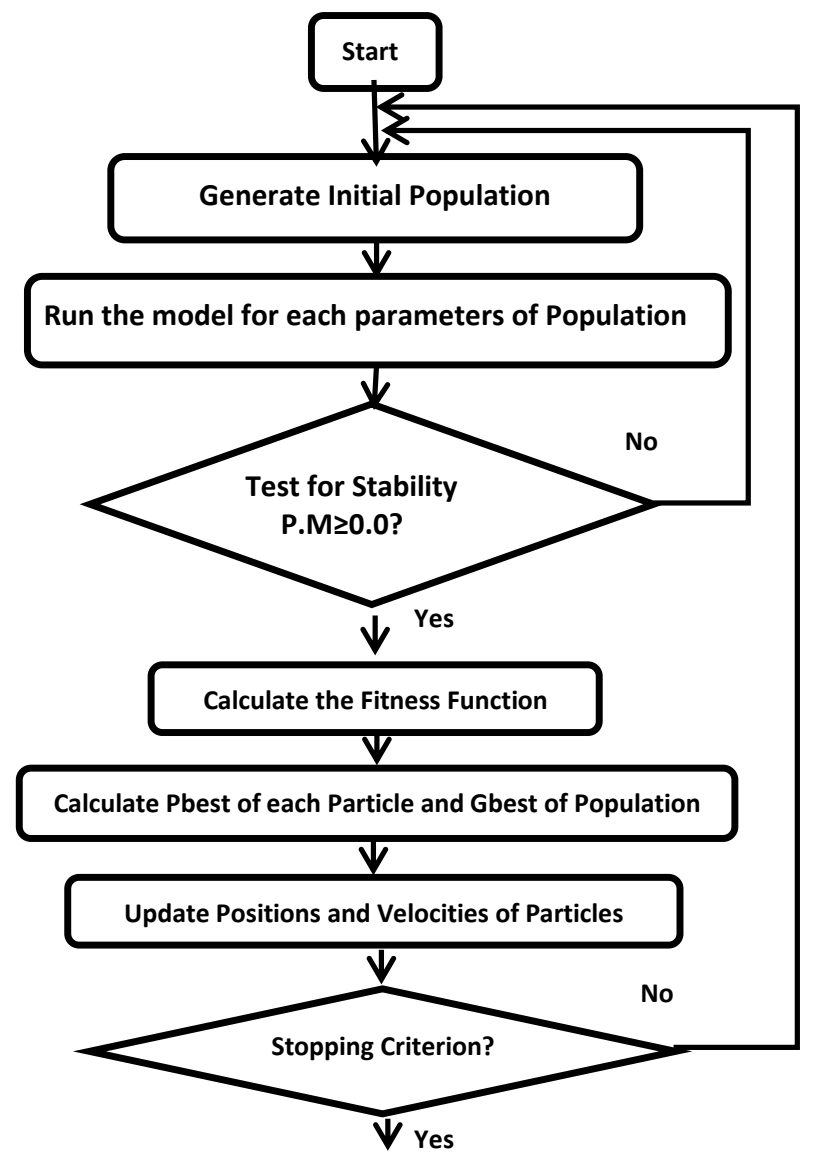

Fig. 1 Flowchart of PSO Controller Design Procedure

In this paper, acceleration constants and inertia weight factor are taken as recommended in Clerc'sPSO [28] where:

$$
\mathrm{C}_{1}=\mathrm{C}_{2}=0.5+\log (2) \text { and } \omega=1 /(2 * \log (2))
$$

The positions are updated based on their movement over a discrete time interval $(\Delta \mathrm{t})$ as follows:

$$
\mathrm{X}_{\mathrm{i}}(\text { new })=\mathrm{X}_{\mathrm{i}}(\text { old })+\mathrm{V}_{\mathrm{i}}(\text { new }) . \Delta \mathrm{t}
$$

Where $\Delta t$ usually is set to 1 . Then the fitness at each position is reevaluated. If any fitness is greater than Gbest, then the new position becomes Gbest, and the particles are accelerated toward the new point. If the particle's fitness value is greater than Pbest, then Pbest is replaced by the current position. The flowchart of PSO algorithm is illustrated in Fig.1.

The PSO algorithm parameters used are:

- 10 particles in each population

- 100 generations

In this Paper, PSO technique is implemented by using MATLAB [28].

\section{EVAPORATION SYSTEM}

The Particle swarm optimization and genetic algorithms are applied to the evaporation system [29]. As shown in Fig. 2, the evaporation system is a forced circulation evaporator that is used to separate mixtures unable to be evaporated by a conventional evaporating unit. This system uses two heat exchangers (evaporator and Condenser) and separation unit (Separator) in conjunction with circulation of the solvent in order to increase the concentration of the feed solution to the required limits. 


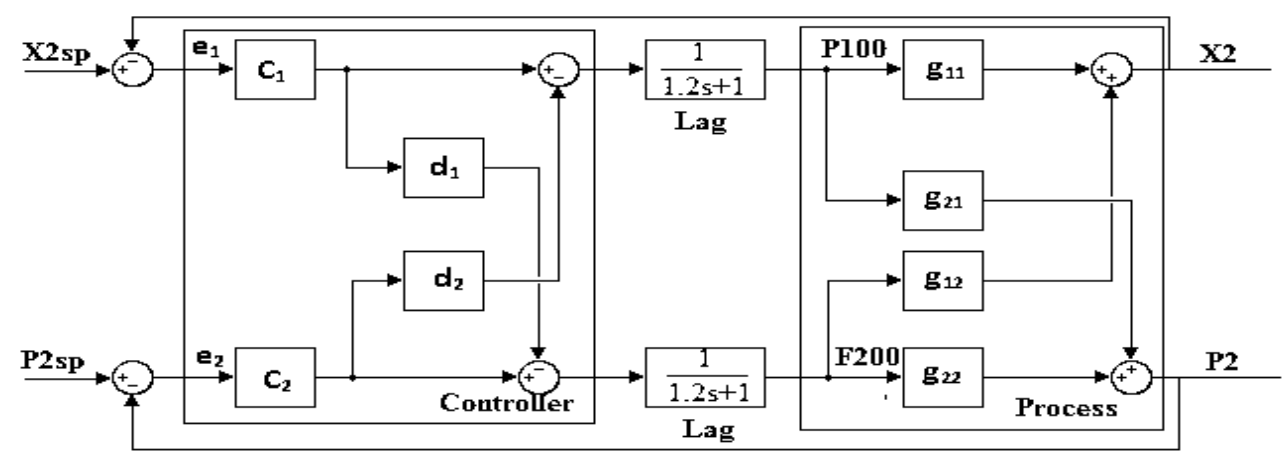

Fig. 3 Multivariable (TITO) process with decoupling controller (controllers $\left[C_{1}\right.$ and $\left.C_{2}\right]$ and decouplers $\left[d_{1}\right.$ and $\left.d_{2}\right]$ )

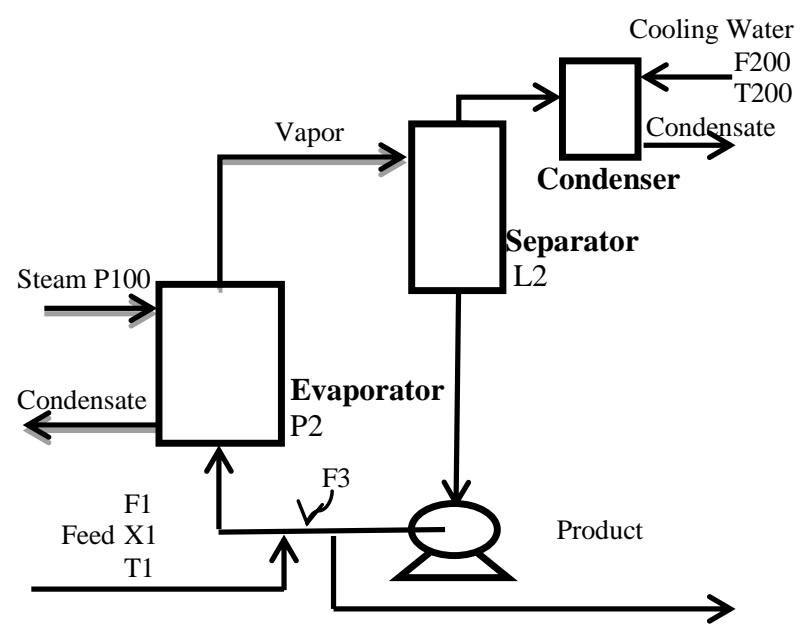

Fig 2: An Evaporator Layout

A mathematical model of the evaporator system was represented as shown in appendix A. A nonlinear mathematical model of the forced circulation evaporator was implemented using SIMULINK/MATLAB [28] as shown in Fig. (1A) in the appendix A.

The corresponding linear state space representation is as follows:

$$
\left[\begin{array}{l}
\dot{L} 2 \\
\dot{X} 2 \\
\dot{P} 2
\end{array}\right]=A\left[\begin{array}{l}
L 2 \\
X 2 \\
P 2
\end{array}\right]+B_{i}\left[\begin{array}{c}
F 2 \\
P 100 \\
F 200
\end{array}\right]+B_{d}\left[\begin{array}{c}
F 3 \\
F 1 \\
X 1 \\
T 1 \\
T 200
\end{array}\right]
$$

$$
\text { Where: } \begin{aligned}
A & =\left[\begin{array}{ccc}
0 & 0.0042 & 0.0075 \\
0 & -0.100 & 0 \\
0 & -0.0209 & -0.0558
\end{array}\right] \\
B_{i} & =\left[\begin{array}{cccc}
-0.0500 & -0.0019 & 0 \\
-0.0125 & 0 & 0 \\
0 & 0.0096 & -0.0018
\end{array}\right] \\
B_{d} & =\left[\begin{array}{ccccc}
-0.0089 & 0.0444 & 0 & -0.0009 & 0 \\
0 & 0.0025 & 0.5000 & 0 & 0 \\
0.0447 & 0.028 & 0 & 0.0045 & 0.036
\end{array}\right]
\end{aligned}
$$

A linear model is obtained from linearization the Simulink model at the nominal operating point as shown in Table $1 \mathrm{~A}$ and Table $2 \mathrm{~A}$ in the appendix $\mathrm{A}$.

The main controlled variable is the "Product Composition" (X2). Also operating pressure (P2) and level of liquid in the separator (L2) are controlled variables for the safe operation and a voiding damaging to the installed equipment. The manipulated variables are; product flow rate (F2), steam pressure (P100) and cooling water flow rate (F200). Other variables that affect the evaporator's performance, act as disturbances, namely F3 (circulating flow rate), F1 (feed flow rate), X1 (feed composition), T1 (feed temperature) and T200 (cooling water flow rate).

\section{IMPLEMENTATION OF \\ EVAPORATOR CONTROL SYSTEM}

\subsection{Implementation of Level Controller}

Considering the proposed PI level controller manipulates the Product Flow rate F2 to adjust separator level L2. According to the proposed cost function that the summation of step response parameters and comparing the results by the two groups of cost functions that by using PSO and GA, Table 1 and Table 2 indicate the obtained optimal parameters of PI controllers (the proportion gain $(\mathrm{Kp})$, integration gain $(\mathrm{Ki})$ ) where each of them with a prefilter which has the gain $(\mathrm{N})$ and pole $(\mathrm{N})$. Also Figures ( $2 \mathrm{a}$ and $2 \mathrm{~b}$ ) show the step response of the proposed level controllers depending on the proposed cost function (SRP) and the other two cost functions groups by using GA and PSO, respectively.

\subsection{Implementation of the Decoupler \\ Controller}

After controlling of the separator level L2 as illustrated in the previous section, the evaporator can be considered as TwoInput-Two-Output (TITO) multivariable system as shown in Figure 3 that by applying a decoupler controller by means of decouplers $d_{1}$ and $d_{2}$ that to cancel the interaction between control loops and leave product composition X2 is controlled only by adjusting steam pressure $\mathrm{P} 100$ and operating pressure P2 is controlled only by adjusting cooling water flow rate F200. Tables $3-6$ indicate by using GA and PSO respectively and according to the different cost functions, the optimal parameters of PI controllers $\mathrm{C} 1$ and lead compensators $\mathrm{C} 2$ of the decoupler controllers and illustrate the comparing results of their summation of step response parameters, gain margin (GM) and phase margin (PM). Also figures (2.1 and 2.2) show the step response of the proposed level controllers using the different cost functions by using GA and PSO, respectively. Also figures (3a, 3b, 4a, and $4 \mathrm{~b}$ ) show the unit step response of the proposed controllers $C_{1}$ and $C_{2}$ relating to the proposed cost function (SRP) and the other two cost functions groups by using GA and PSO, respectively. Table 7 summarizes the best results of the two cost functions groups and the results of the suggested cost function SRP by using GA and PSO strategies. 

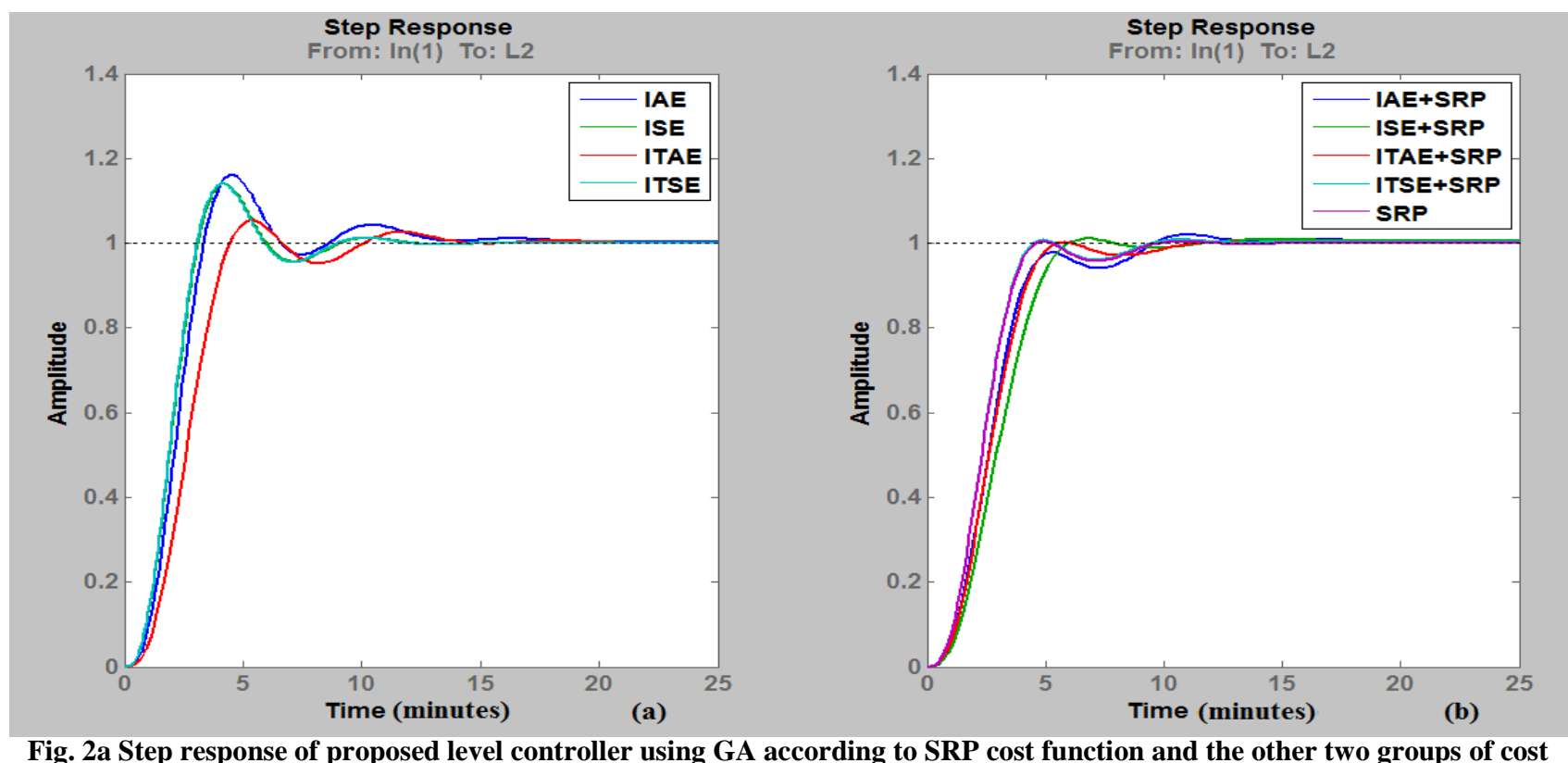

Fig. 2a Step response of proposed level controller using GA according to SRP cost function and the other two groups of cost functions

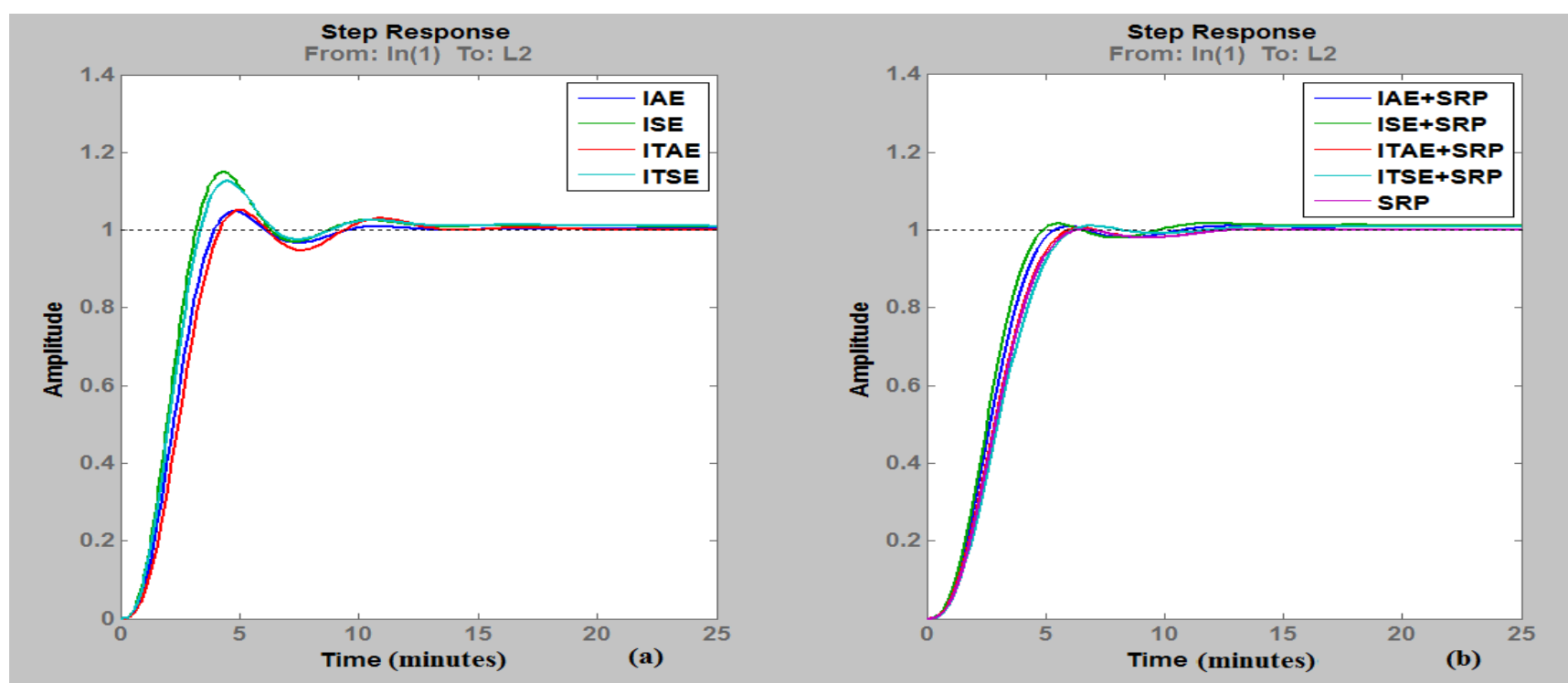

Fig. 2b Step response of proposed level controller using PSO according to SRP cost function and the other two groups of cost functions

Table 1 Parameters of proposed Level controllers using GA with two groups of cost functions and SRP cost function, also summation of step response parameters (SRP values), their gain margin (GM) and phase margin (PM) (the dashed row indicates its best in SRP or Stability)

\begin{tabular}{|c|c|c|c|c|c|c|c|c|c|c|c|c|c|}
\hline $\begin{array}{l}\text { First } \\
\text { group }\end{array}$ & Kp & $\mathbf{K i}$ & $\mathbf{N}$ & SRP & $\begin{array}{l}\text { GM } \\
\text { (dB) }\end{array}$ & $\begin{array}{c}\text { PM } \\
\text { (deg) }\end{array}$ & $\begin{array}{l}\text { Second } \\
\text { group } \\
+ \text { +SRP }\end{array}$ & Kp & $\mathbf{K i}$ & $\mathbf{N}$ & SRP & $\begin{array}{l}\text { GM } \\
\text { (dB) }\end{array}$ & $\begin{array}{c}\text { PM } \\
\text { (deg) }\end{array}$ \\
\hline IAE & 30 & 4.8219 & 0.6365 & 30.33 & Inf & 48.19 & IAE+SRP & 29.6782 & 5.3991 & 0.3724 & 13.8 & Inf & 46.54 \\
\hline ISE & 29.286 & 0.0001 & 1 & 24.26 & Inf & 64.36 & ISE+SRP & 18.3726 & 0.1333 & 0.5024 & 10 & Inf & 83.22 \\
\hline ITAE & 25.995 & 5.9177 & 0.3998 & 20.64 & Inf & 45.15 & ITAE+SRP & 23.1784 & 0.0037 & 0.5279 & 12.63 & Inf & 73.53 \\
\hline ITSE & 30 & 0.0004 & 1 & 24.24 & Inf & 63.5 & ITSE+SRP & 29.9937 & 0.1781 & 0.5626 & 11.75 & Inf & 62.91 \\
\hline & & & & & & & SRP & 29.7838 & 0.0001 & 0.5643 & 11.55 & inf & 63.760 \\
\hline
\end{tabular}


Table 2 Parameters of proposed Level controllers using PSO with two groups of cost functions and SRP cost function, also summation of step response parameters (SRP values), their gain margin (GM) and phase margin (PM) (the dashed row indicates its best in SRP or Stability)

\begin{tabular}{|c|c|c|c|c|c|c|c|c|c|c|c|c|c|}
\hline $\begin{array}{l}\text { First } \\
\text { group }\end{array}$ & Kp & $\mathbf{K i}$ & $\mathbf{N}$ & SRP & $\begin{array}{l}\text { GM } \\
\text { (dB) }\end{array}$ & $\begin{array}{l}\text { PM } \\
\text { (deg) }\end{array}$ & $\begin{array}{l}\text { Second } \\
\text { group +SRP }\end{array}$ & $\mathbf{K p}$ & $\mathbf{K i}$ & $\mathbf{N}$ & SRP & $\begin{array}{l}\text { GM } \\
\text { (dB) }\end{array}$ & $\begin{array}{l}\text { PM } \\
\text { (deg) }\end{array}$ \\
\hline IAE & 28.3932 & 0.1079 & 0.6521 & 15.62 & Inf & 65.09 & IAE+SRP & 22.3411 & 0.2295 & 0.5171 & 8.97 & inf & 73.75 \\
\hline ISE & 28.8048 & 0.6705 & 0.9224 & 28.20 & Inf & 62.54 & ISE+SRP & 24.9458 & 0.5603 & 0.5232 & 9.09 & inf & 67.81 \\
\hline ITAE & 29.1052 & 6.384 & 0.4272 & 19.69 & Inf & 43.65 & ITAE+SRP & 19.2738 & 0.0019 & 0.5172 & 9.28 & inf & 82.03 \\
\hline ITSE & 28.4603 & 0.7569 & 0.8196 & 26.30 & Inf & 62.60 & ITSE+SRP & 17.6662 & 0.1461 & 0.4945 & 10.25 & inf & 85.03 \\
\hline & & & & & & & SRP & 19.0901 & 0.0118 & 0.5039 & 9.09 & inf & 82.43 \\
\hline
\end{tabular}

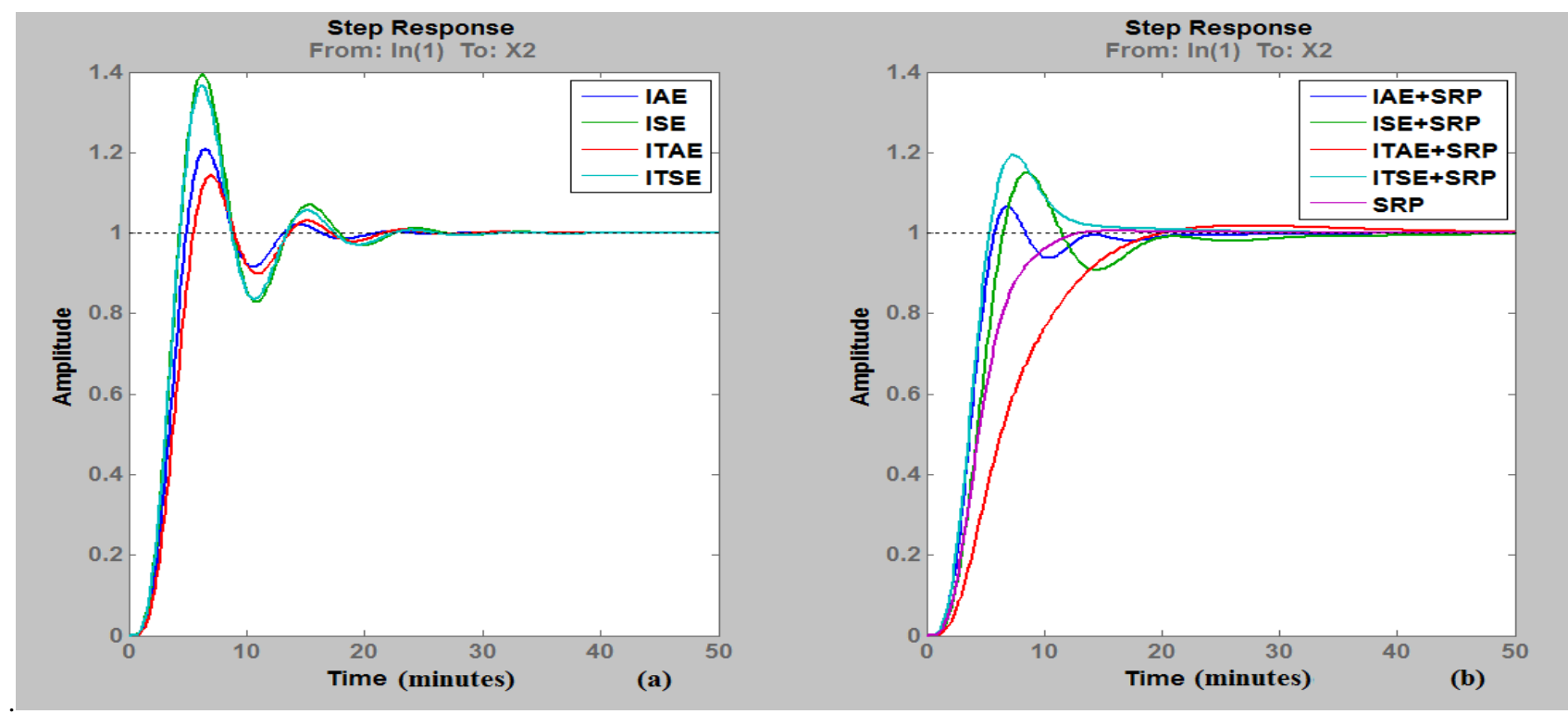

Fig. 3a Step response of proposed controllers $C_{1}$ using GA according to SRP cost function and the other two groups of cost functions
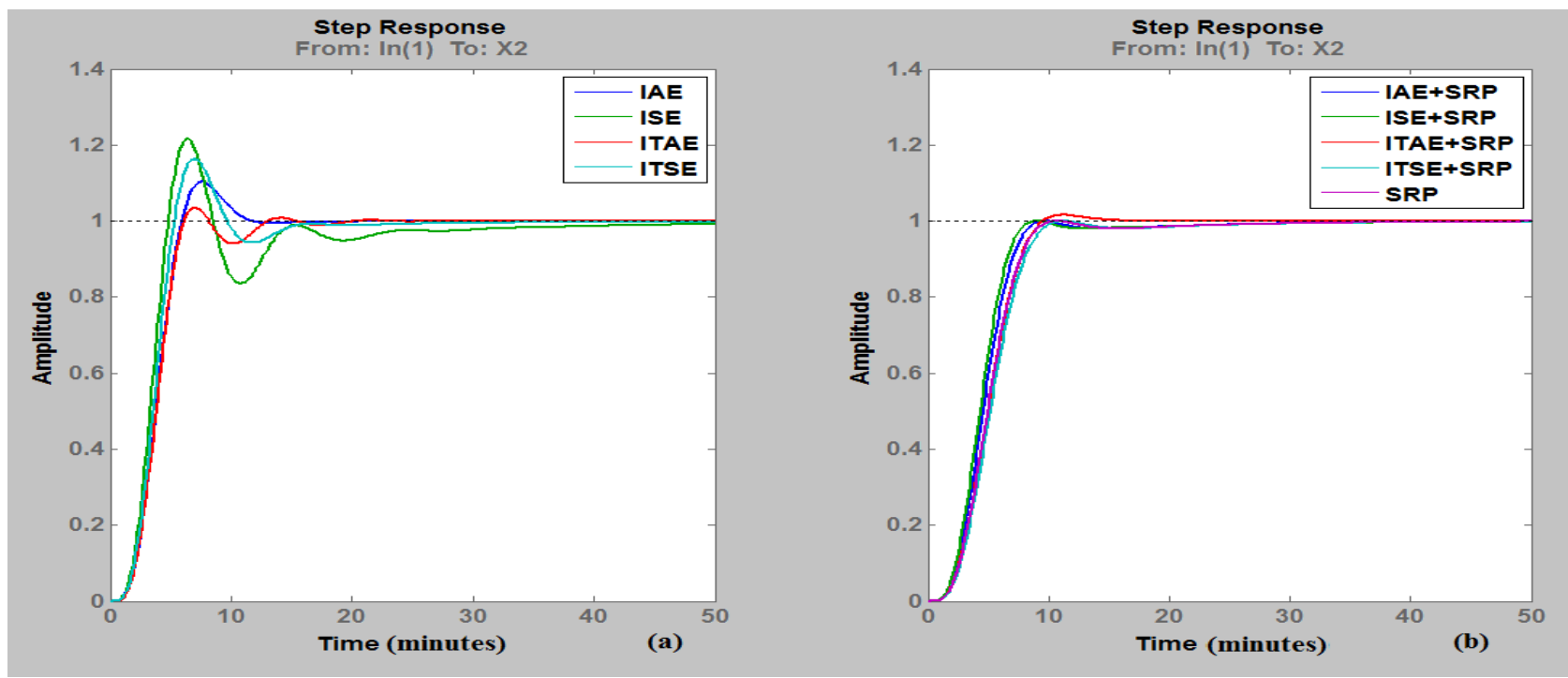

Fig. 3b Step response of proposed controllers $C_{1}$ using PSO according to SRP cost function and the other two groups of cost functions 
Table 3 Parameters of proposed controllers $\mathrm{C}_{1}$ using GA with two groups of cost functions and SRP cost function, also summation of step response parameters (SRP values), their gain margin (GM) and phase margin (PM) (the dashed row indicates its best in SRP or Stability)

\begin{tabular}{|c|l|l|l|l|l|l|l|l|l|l|l|}
\hline $\begin{array}{l}\text { First } \\
\text { group }\end{array}$ & Kp & Ki & SRP & $\begin{array}{l}\text { GM } \\
(\mathrm{dB})\end{array}$ & $\begin{array}{l}\text { PM } \\
(\mathrm{deg})\end{array}$ & $\begin{array}{l}\text { Second } \\
\text { group } \\
\text { +SRP }\end{array}$ & Kp & Ki & SRP & GM & PM \\
$(\mathrm{dB})$ & $(\mathrm{deg})$ \\
\hline IAE & 689.472 & $\mathbf{7 0 . 3 7 7 4}$ & $\mathbf{3 8 . 2 7}$ & 1.9443 & $\mathbf{5 5 . 2 3}$ & IAE+SRP & 567.387 & 54.5581 & 22.26 & 2.29 & 64.04 \\
\hline ISE & 964.093 & $\mathbf{9 4 . 6 0 5 8}$ & 62.77 & 1.6955 & 40.96 & ISE+SRP & 602.353 & 46.5112 & 37.52 & 2.27 & 56.41 \\
\hline ITAE & 572.376 & 59.039 & 36.74 & 1.9544 & 61.76 & ITAE+SRP & 253.6 & 30.012 & 30.12 & 5.69 & 70.21 \\
\hline ITSE & 960.395 & $\mathbf{8 7 . 6 7 0 1}$ & 59.52 & 1.7308 & 42.75 & ITSE+SRP & 653.085 & 83.8868 & 36.1 & 2.45 & 51.6 \\
\hline
\end{tabular}

Table 4 Parameters of proposed controllers $C_{1}$ using PSO with two groups of cost functions and SRP cost function, also summation of step response parameters (SRP values), their gain margin (GM) and phase margin (PM) (the dashed row indicates its best in SRP or Stability)

\begin{tabular}{|c|c|c|c|c|c|c|c|c|c|c|c|}
\hline $\begin{array}{l}\text { First } \\
\text { group }\end{array}$ & Kp & $\mathbf{K i}$ & SRP & $\begin{array}{l}\text { GM } \\
\text { (dB) }\end{array}$ & $\begin{array}{l}\text { PM } \\
\text { (deg) }\end{array}$ & $\begin{array}{l}\text { Second } \\
\text { group } \\
\text { +SRP }\end{array}$ & Kp & $\mathbf{K i}$ & SRP & $\begin{array}{l}\text { GM } \\
\text { (dB) }\end{array}$ & $\begin{array}{l}\text { PM } \\
\text { (deg) }\end{array}$ \\
\hline IAE & 616.533 & 61.4936 & 24.0605 & 2.5967 & 58.2297 & IAE+SRP & 465.708 & 42.309 & 12.80 & 3.09 & 65.59 \\
\hline ISE & 848.505 & 50.1403 & 55.8227 & 1.9088 & 52.225 & ISE+SRP & 489.623 & 44.357 & 11.96 & 3.03 & 65.40 \\
\hline ITAE & 521.072 & 54.4077 & 18.9635 & 2.3397 & 65.8306 & ITAE+SRP & 421.334 & 42.3508 & 15.50 & 3.25 & 64.08 \\
\hline ITSE & 703.938 & 61.4962 & 33.6499 & 2.2298 & 55.5638 & ITSE+SRP & 410.02 & 37.741 & 14.77 & 3.22 & 65.89 \\
\hline & & & & & & SRP & 432.247 & 39.525 & 14.09 & 3.19 & 65.80 \\
\hline
\end{tabular}

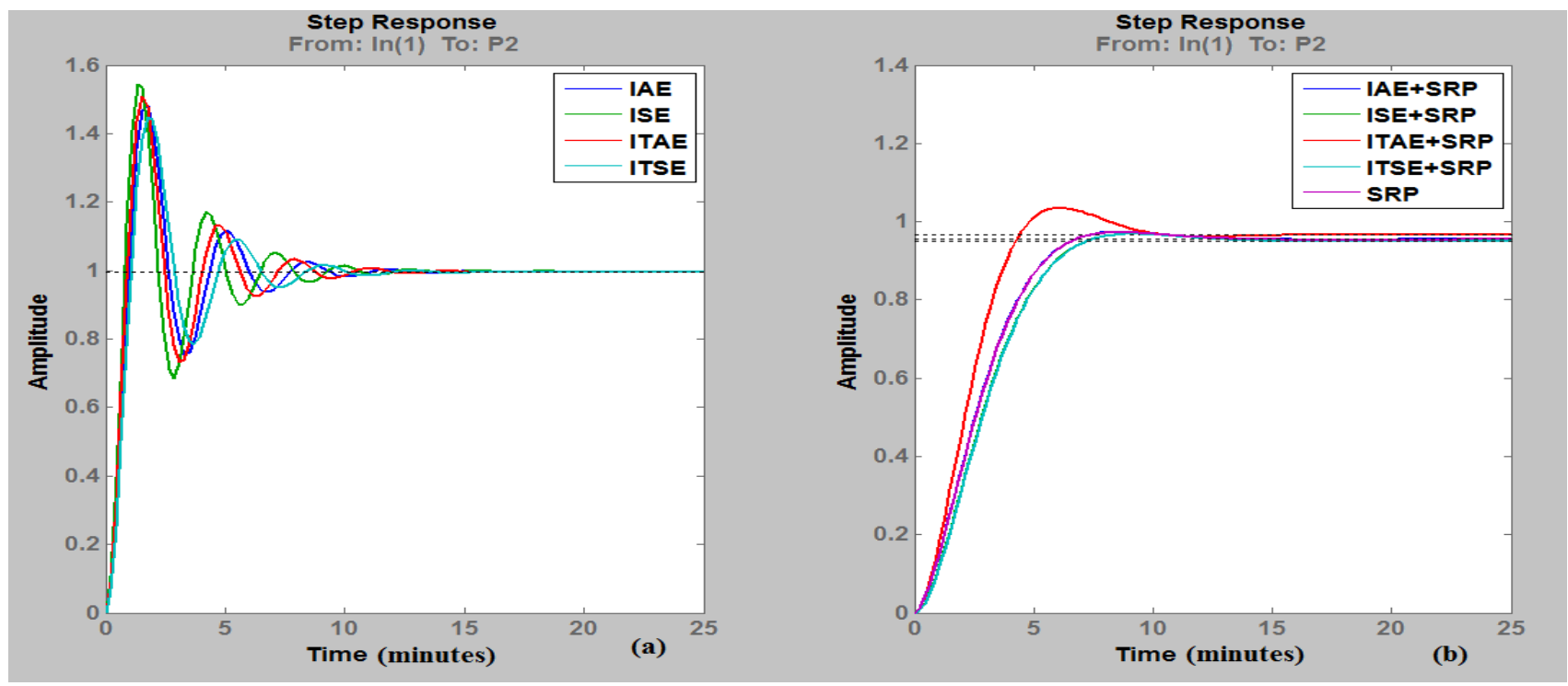

Fig. 4a Step response of proposed controllers $C_{2}$ using GA according to SRP cost function and the other two groups of cost functions 


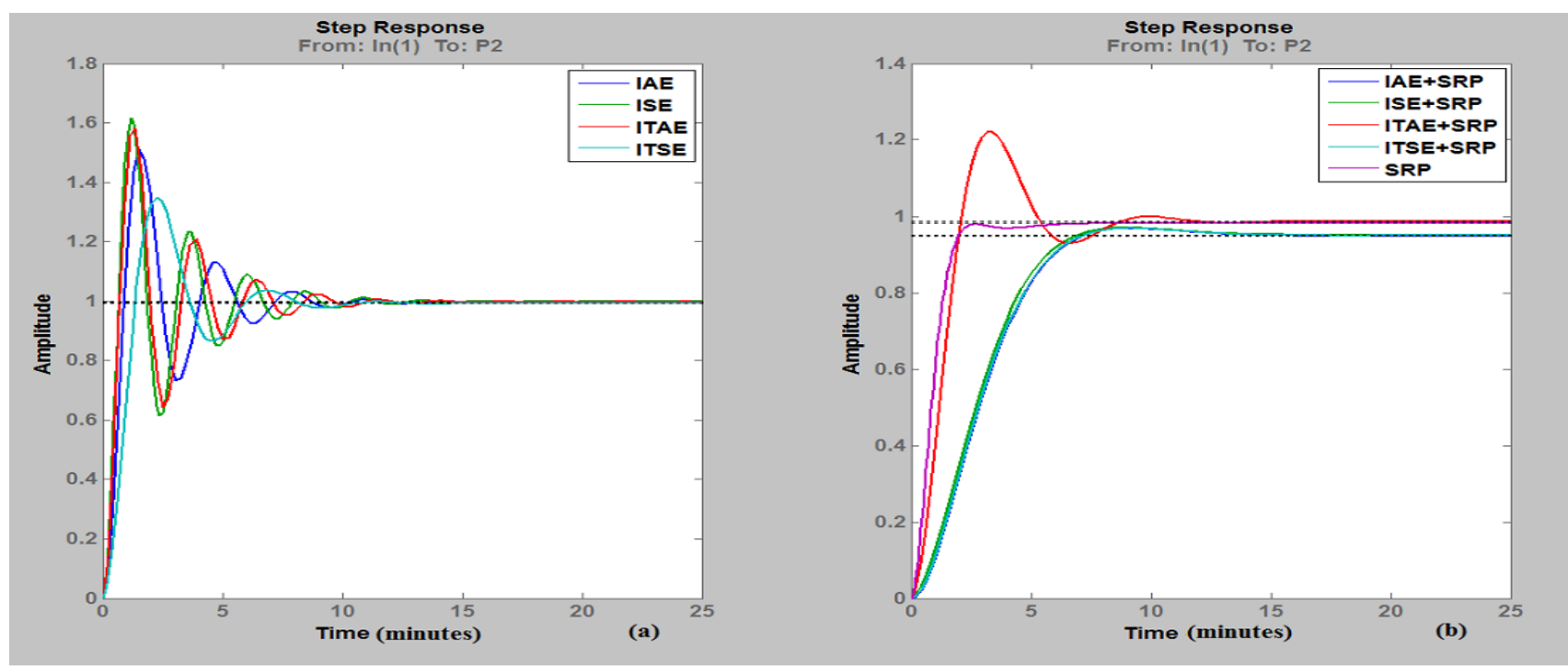

Fig. 4b Step response of proposed controllers $\mathrm{C}_{2}$ using PSO according to SRP cost function and the other two groups of cost functions

Table 5 Parameters of proposed $\mathrm{C}_{2}$ using GA with two groups of cost functions and SRP cost function, also summation of step response parameters (SRP values), their gain margin (GM) and phase margin (PM) (the dashed row indicates its best in SRP or Stability)

\begin{tabular}{|c|c|c|c|c|c|c|c|c|c|c|c|c|c|}
\hline $\begin{array}{l}\text { First } \\
\text { group }\end{array}$ & $\mathbf{z}$ & $\mathbf{p}$ & $\mathbf{k}$ & SRP & $\begin{array}{l}\text { GM } \\
\text { (dB) }\end{array}$ & $\begin{array}{l}\text { PM } \\
\text { (deg) }\end{array}$ & $\begin{array}{l}\text { Second } \\
\text { group +SRP }\end{array}$ & $\mathbf{z}$ & p & $\mathbf{k}$ & SRP & $\begin{array}{l}\text { GM } \\
\text { (dB) }\end{array}$ & $\begin{array}{l}\text { PM } \\
\text { (deg) }\end{array}$ \\
\hline IAE & -113.6 & -78.9 & -1660.1 & 58.48 & 62.58 & 24.78 & IAE+SRP & -6 & -40.6 & -1401.6 & 12.31 & inf & 73.08 \\
\hline ISE & -166.8 & -77.7 & -1554.6 & 64.27 & 24.86 & 20.55 & ISE+SRP & -34 & -169.3 & -936.3 & 12.92 & inf & 72.57 \\
\hline ITAE & -200 & -117.1 & -1592.6 & 60.61 & 59.06 & 23.25 & ITAE+SRP & -29.8 & -153.3 & -1469.3 & 19.02 & inf & 64.22 \\
\hline ITSE & -162.8 & -151 & -1909.9 & 55.46 & 612.81 & 27.01 & ITSE+SRP & -77.4 & -189.6 & -457.3 & 13 & inf & 72.5 \\
\hline & & & & & & & SRP & -6.07 & -41.17 & $-1.40 E+03$ & 12.32 & inf & 73.09 \\
\hline
\end{tabular}

Table 6 Parameters of proposed $C_{2}$ using PSO with two groups of cost functions and SRP cost function, also summation of step response parameters (SRP values), their gain margin (GM) and phase margin (PM) (the dashed row indicates its best in SRP or Stability)

\begin{tabular}{|c|c|c|c|c|c|c|c|c|c|c|c|c|c|}
\hline $\begin{array}{l}\text { First } \\
\text { group }\end{array}$ & $\mathbf{Z}$ & $\mathbf{p}$ & $\mathbf{k}$ & SRP & $\begin{array}{l}\text { GM } \\
\text { (dB) }\end{array}$ & $\begin{array}{l}\text { PM } \\
\text { (deg) }\end{array}$ & $\begin{array}{l}\text { Second } \\
\text { group +SRP }\end{array}$ & $\mathbf{z}$ & $\mathbf{p}$ & $\mathbf{k}$ & SRP & $\begin{array}{l}\text { GM } \\
\text { (dB) }\end{array}$ & $\begin{array}{l}\text { PM } \\
\text { (deg) }\end{array}$ \\
\hline IAE & -166.5 & -114.3 & -1870.3 & 60.47 & 76.58 & 23.32 & IAE+SRP & -70.8 & -125.1 & -329.47 & 13.01 & Inf & 72.49 \\
\hline ISE & -149.4 & -65.2 & -1980.5 & 72.13 & 14.58 & 17.14 & ISE+SRP & -11.8 & -118.32 & $-1.97 E+03$ & 12.66 & Inf & 72.81 \\
\hline ITAE & -135.7 & -65.5 & -1955.1 & 68.15 & 17.91 & 18.39 & ITAE+SRP & -42.1 & -94.91 & $-1.59 E+03$ & 19.13 & Inf & 45.15 \\
\hline ITSE & -15.1 & -22.2 & -1982.2 & 44.47 & Inf & 34.67 & ITSE+SRP & -38.2 & -169.63 & -835.78 & 12.4 & Inf & 12.94 \\
\hline & & & & & & & SRP & -0.68 & -2.40 & -2000 & 3.61 & Inf & 72.01 \\
\hline
\end{tabular}

Table 7 A comparison between the results of Using GA and PSO in optimal evaporator control system

\begin{tabular}{|c|l|l|l|l|}
\hline \multirow{2}{*}{$\begin{array}{c}\text { Controlled } \\
\text { parameter }\end{array}$} & Cost functions & & GA & PSO \\
\hline \multirow{2}{*}{ L2 } & \multirow{2}{*}{ First group } & Best Performance & ITAE, SRP=20.64 & IAE, SPR=15.62 \\
\cline { 3 - 6 } & & Best Stability & ISE, GM=inf, PM=64.36 & IAE, GM= inf, PM=65.69 \\
\hline
\end{tabular}




\begin{tabular}{|c|c|c|c|c|}
\hline & \multirow[b]{2}{*}{ Second group } & Best Performance & ISE+SRP, SRP=9.99 & $\mathrm{IAE}+\mathrm{SEP}, \mathrm{SRP}=8.97$ \\
\hline & & Best Stability & $\begin{array}{l}\text { ISE+SRP, GM= inf, } \\
\mathrm{PM}=83.22\end{array}$ & $\begin{array}{l}\text { ITAE+SEP, GM=inf, } \\
\mathrm{PM}=85.03\end{array}$ \\
\hline & \multirow{2}{*}{ SRP } & Best Performance & $\mathrm{SRP}=11.55$ & $\mathrm{SRP}=9.09$ \\
\hline & & Best Stability & $\mathrm{GM}=$ inf, $\mathrm{PM}=63.76$ & GM1=inf, $\mathrm{PM} 1=82.43$ \\
\hline \multirow{6}{*}{$\mathrm{X} 2$} & \multirow{2}{*}{ First group } & Best Performance & ITAE, SRP=36.74 & ITAE, SRP=18.96 \\
\hline & & Best Stability & ITAE, $\mathrm{GM}=1.95, \mathrm{PM}=61.76$ & ITAE, $\mathrm{GM}=2.34, \mathrm{PM}=65.83$ \\
\hline & \multirow{2}{*}{ Second group } & Best Performance & $\mathrm{IAE}+\mathrm{SRP}, \mathrm{SRP}=22.26$ & ISE+SRP, SRP=11.96 \\
\hline & & Best Stability & $\begin{array}{l}\text { ITAE+SRP, GM=5.69, } \\
\mathrm{PM}=70.2\end{array}$ & $\begin{array}{l}\text { ISE+SRP GM=3.03, PM= } \\
65.40\end{array}$ \\
\hline & \multirow{2}{*}{ SRP } & Best Performance & $\mathrm{SRP}=17.16$ & $\mathrm{SRP}=14.09$ \\
\hline & & Best Stability & $\mathrm{GM}=3.83, \mathrm{PM}=67.59$ & $\mathrm{GM}=3.19, \mathrm{PM}=65.80$ \\
\hline \multirow{6}{*}{$\mathrm{P} 2$} & \multirow{2}{*}{ First group } & Best Performance & ITAE, SRP=52.2 & ITSE, SRP $=44.47$ \\
\hline & & Best Stability & ITSE, GM=612.8, PM=27.01 & ITSE, GM=inf, PM=34.66 \\
\hline & \multirow{2}{*}{ Second group } & Best Performance & $\mathrm{IAE}+\mathrm{SRP}, \mathrm{SRP}=12.31$ & ISE+SRP, SRP=12.66 \\
\hline & & Best Stability & $\begin{array}{l}\text { IAE+SRP, GM=inf, } \\
\mathrm{PM}=73.08\end{array}$ & $\begin{array}{l}\text { ITSE+SRP,GM=inf, PM= } \\
72.81\end{array}$ \\
\hline & \multirow{2}{*}{ SRP } & Best Performance & $\mathrm{SRP}=12.32$ & $\mathrm{SRP}=3.61$ \\
\hline & & Best Stability & $\mathrm{GM}=$ inf, $\mathrm{PM}=73.09$ & $\mathrm{GM}=$ inf, $\mathrm{PM}=72.01$ \\
\hline
\end{tabular}

\section{ANALYSIS OF RESULTS}

From previous results it could be concluded that:-

- The proposed implemented PSO achieves a best trade-off between performance and stability over than GA algorithm for tuning a level controller and a decoupler controller for the evaporator system.

- By using PSO and GA strategies the proposed cost function (SRP) achieves best performance and stability for the evaporator control system than the first group of cost functions; such as (IAE, ISE, ITAE, and ITSE) . Also SRP cost function gives best results in performance and stability for the evaporator control system near the best results of the second groups of cost functions. Moreover this cost function by using PSO achieves best performance in control operating pressure $\mathrm{P} 2$ over than the other two groups of cost functions.

-Figures (5a, 5b, 6a and 6b) confirm that ideal decoupler is achieved by using the proposed PSO and GA for the decoupler controllers for the evaporator system depending on the proposed SRP cost function and the other two groups of cost functions.
-Tables (8-11) show the degree of the robustness of the proposed evaporator control systems using GA and PSO depending on the proposed SRP cost function and the other two groups of cost functions with respect to changing the disturbance feed flow rate $\mathrm{F} 1$ by $30 \%$ decrease)

\section{CONCLUSION}

In this paper a particle swarm optimization algorithm is implemented as an intelligent procedure for designing of optimal evaporator control system. Simulation results demonstrate that our proposed method using cost function of summation of step response parameters (SRP) such; rise time $\mathrm{Tr}$, settling time $\mathrm{Ts}$, maximum overshoot $\mathrm{Mp}$ and steady state error Ess. is more efficient, stability and robust compared with the ordinary tuning methods using performance indices only. Also the proposed PSO achieves superiority over GA algorithm.

\section{ACKNOWLEDGMENTS}

Our thanks to the colleagues of Hot Laboratory and Waste Management Center, Atomic Energy Authority, especially Prof. Dr. A. M. El-kamash, who have contributed towards the development of this work.

\section{Appendix A:}

Table 1a. Steady-State of the Evaporator Plant for the Inputs

\begin{tabular}{|c|c|c|c|c|c|c|c|}
\hline F2 & P100 & F200 & F3 & F1 & X1 & T1 & T200 \\
{$[\mathrm{Kg} / \mathrm{min}]$} & {$[\mathrm{Kpa}]$} & {$[\mathrm{Kg} / \mathrm{min}]$} & {$[\mathrm{Kg} / \mathrm{min}]$} & {$[\mathrm{Kg} / \mathrm{min}]$} & {$[\%$ of mass $]$} & {$\left[{ }^{\circ} \mathrm{C}\right]$} & {$\left[{ }^{\circ} \mathrm{C}\right]$} \\
\hline 2.0 & 194.7 & 208.0 & $\mathbf{5 0 . 0}$ & 10.0 & 5.0 & 40.0 & 25.0 \\
\hline
\end{tabular}

Table 2a. Steady-State of the Evaporator Plant for the Outputs.

\begin{tabular}{|c|c|c|}
\hline L2 [m] & X2 [\%of mass] & P2[Kpa] \\
\hline 1.0 & 25.0 & 50.5 \\
\hline
\end{tabular}




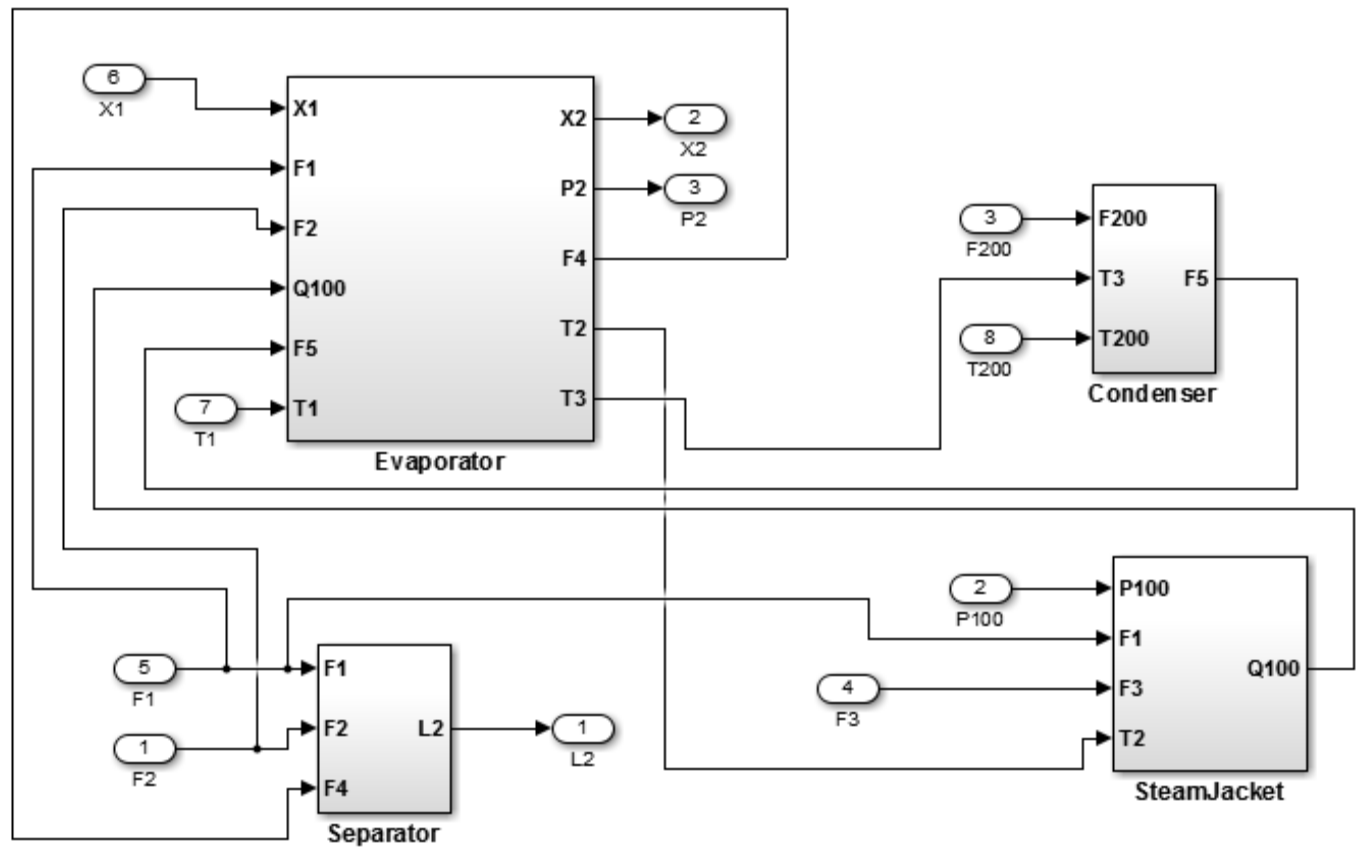

Fig 1a: A simulink model of the forced circulation evaporator consists of subsystems $\left({ }^{1}\right.$ separator, ${ }^{2}$ evaporator, ${ }^{3}$ condenser, ${ }^{4}$ steam jacket)

\section{REFERENCES}

[1] N. Gowtham; Shobha Shankar, "PI tuning of Shunt Active Filter using GA and PSO algorithm", 2nd International Conference on Advances in Electrical, Electronics, Information, Communication and BioInformatics (AEEICB),(2016) 207-213, IEEE Conference Publications

[2] V. Pano; P. R. Ouyang, "Comparative study of GA, PSO, and DE for tuning position domain PID controller",IEEE International Conference on Robotics and Biomimetics, (ROBIO 2014) 1254-1259, IEEE Conference Publications

[3] Sheikh Abid Hossain; Sourav Roy; Animesh Karmaker; Md. Rafiqul Islam , "Performance improvement of PID controller for AVR system using Particle Swarm Optimization", 2015 International Conference on Advances in Electrical Engineering (ICAEE), (2015) 243 - 246, IEEE Conference Publications

[4] Guangyu Li; Chen Guo; Yanxin Li; Wu Deng, "Fractional-Order PID Controller of USV CourseKeeping Using Hybrid GA-PSO Algorithm”, 2015 8th International Symposium on Computational Intelligence and Design (ISCID)( 2015), Vol. 2, pp. 506 - 509, IEEE Conference Publications

[5] El-Sayed M. Ahmed; Mohamed. M. Ismail, "PID controller tunning scheme for TRMS using AI techniques", 2012 8th International Computer Engineering Conference (ICENCO), (2012) 37 - 42, IEEE Conference Publications

[6] K. Jagatheesan; B. Anand; Nillanjan Dey; Tarek Gaber; Aboul Ella Hassanien; Tai-Hoon Kim, "A Design of PI Controller using Stochastic Particle Swarm Optimization in Load Frequency Control of Thermal Power Systems", 2015 Fourth International Conference on Information
Science and Industrial Applications (ISI), (2015) 25 - 32, IEEE Conference Publications

[7] Fariborz Mirlou Miavagh; Easa Ali Abbasi Miavaghi; Amir Rikhtegar Ghiasi;Mostafa Asadollahi, "Applying of PID, FPID, TID and ITID controllers on AVR system using particle swarm optimization (PSO)",2015 2nd International Conference on Knowledge-Based Engineering and Innovation (KBEI), IEEE Conference Publications

[8] Hengameh Noshahri; Hamed Kharrati, "PID controller design for unmanned aerial vehicle using genetic algorithm", 2014 IEEE 23rd International Symposium on Industrial Electronics (ISIE), (2014) 213 - 217, IEEE Conference Publications

[9] Naeim Farouk Mohammed; Xiuzhen Ma; Enzhe Song, "Tuning of PID controller for diesel engines using genetic algorithm", 2013 IEEE International Conference on Mechatronics and Automation, (2013) 1523-1527, IEEE Conference Publications

[10] Naeim Farouk Mohammed; Enzhe Song; Xiuzhen Ma; Qaisar Hayat, "Tuning of PID controller of synchronous generators using genetic algorithm", 2014 IEEE International Conference on Mechatronics and Automation, (2014) 1544-1548, IEEE Conference Publications

[11] Singh, R.; Kuchhal, P.; Choudhury, S.; and Gehlot, A., "Implementation and Evaluation of Heating System using PID with Genetic Algorithm", Indian Journal of Science and Technology, Vol.8 No. 5(2015) 413-8.

[12] Deepa Thangavelusamy, Lakshmi Ponnusamy, "Comparison of PI controller tuning using GA and PSO for a Multivariable Experimental Four Tank System", 
International Journal of Engineering and Technology (IJET), Vol.5. No. 6, (Dec 2013-Jan 2014) 4660-4671.

[13] Angeline Vijula Dhanraj and Devarajan Nanjundappan ,"Design of Optimized PI Controller with ideal Decoupler for A non Linear Multivariable System Using Particle Swarm Optimization", International Journal of Innovative Computing, Information and Control ICIC International, 2014 ISSN 1349-4198, Vol. 10. No. 1, (February 2014 ) 341-355

[14] Boubertakh, H.; Labiod, S.; and M., "PSO to Design Decentralized Fuzzy PI Controllers Application for a Helicopter', 20th Mediterranean Conference on Control \& Automation (MED), Barcelona, Spain, 2012.

[15] Zhao, S.-Z., Iruthayarajan, M. Willjuice; Baskar, S.; Suganthan, P.N., "objective robust PID controller tuning using two lbests multi objective particle swarm optimization", Information Sciences, Vol. 181 No. 16(2011) 3323-3335.

[16] Iruthayarajan, M. Willjuice and Baskar, S. "Evolutionary algorithms based design of multivariable PID controller', Expert Systems with Applications, Vol. 36 No. 5(2009) 9159-9167.

[17] Han, Kai; Zhao, Jun; Xu, Zu-hua; and Qian, Ji-xin. “A closed-loop particle swarm optimizer for multivariable process controller design", Journal of Zhejiang University-Science A, Vol. 9 No. 8( 2008) 1050-1060.

[18] Jiangjiang Wang, Youyin Jing and Chunfa Zhang, "Genetic optimization algorithm on PID decoupling controller for variable flow heating system", Industrial Electronics and Applications, 2008. ICIEA 2008. 3rd IEEE Conference on, 3-5 June 2008.

[19] Su, C. T.; Wong, J. T., ' 'Designing MIMO controller by neuro-traveling particle swarm optimizer approach", International Expert Systems with Applications, 32(2007) 848-855, available:http://homes.esat.kuleuven.be/ smc/daisy/daisy data.html

[20] Chang, W. D., "A multi-crossover genetic approach to multivariable PID controllers tuning', International Expert Systems with Applications, 33(2007) 620-626.
[21] Haupt, R. L. and Haupt, S. E., "Practical Genetic Algorithms", 2nd ed., John Wiley \&Sons, Inc., 2004.

[22] Kennedy, J. and Eberhart R. , "Particle swarm optimization", in Proceedings of IEEE International Conference of Neural Networks, Vol. IV, 1995 Perth, Australia, pp. 1942-1948.

[23] Zamani, M., Karimi-Ghartemani, M., Sadati, N. and Parniani, M., "Design of a fractional order PID controller for an AVR using particle swarm ptimization", Control Eng Pract 2009;17(12):1380-7.

[24] Hamidi, J., "Control System Design Using Particle Swarm Optimization (PSO)", and International Journal of Soft Computing and Engineering (IJSCE), ISSN: 2231-2307, Vol. 1, Issue-6, January 2012, pp. 116-119.

[25] Abdel-Halim, Hala A. et al., " A Comparative Study of Intelligent Control System Tuning Methods for an Evaporator Based on Genetic Algorithm", International Journal of Applied Information Systems (IJAIS), ISSN : 2249-0868, Foundation of Computer Science FCS, New York, USA, Volume 11- No.10,Febrauary 2017 available on : www.ijais.org

[26] Stanley M. Shinners," Modern Control System Theory and Design", 1998, John Wiley and Sons Ltd, New York, United States.

[27] Hassanzadeh, Iraj and Mobayen, Saleh, "Optimum design of PID controller for 5-bar-linkage manipulator using particle swarm optimization", in Proceeding of the 4th International Symposium on Mechatronics and its applications.

[28] Clerc, M., "The Swarm and the queen: towards a deterministic and adaptive particle swarm optimization", in Proceedings of the Conference on Evolutionary Computation, (1999). 1951-7. Applications (ISMA07), Sharjah, U.A.E., 2007.

[29] MATLAB Version 8.3.0.532 R2014a, 32-bit (win32), February 11, 2014.

[30] Newell, R. B. and Lee, P. L., “ 'Applied Process Control: A case study", Prentice-Hall of Australia Ltd., 1989. 


\section{APPENDIX}

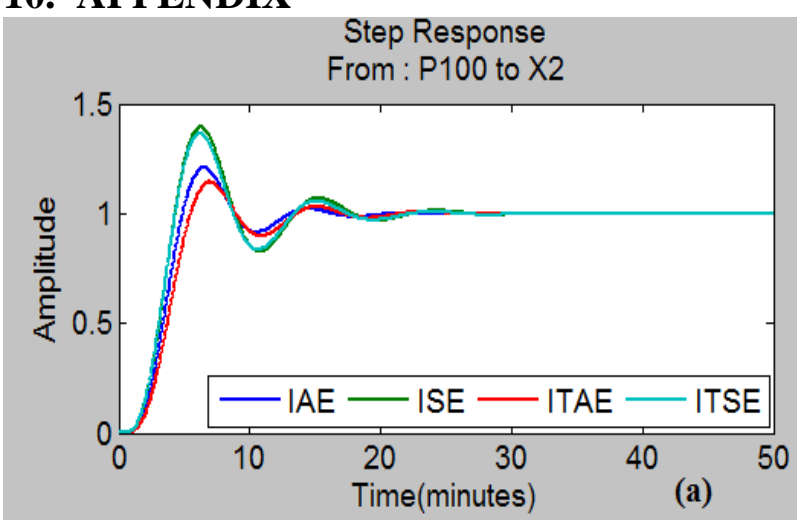

Step Response

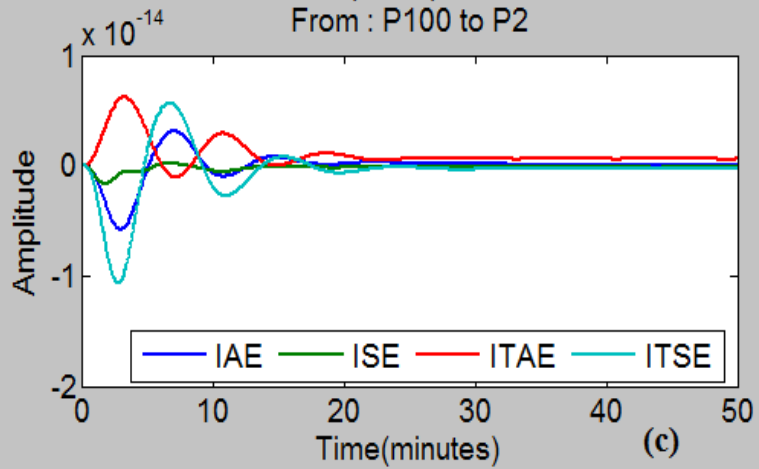

Step Response

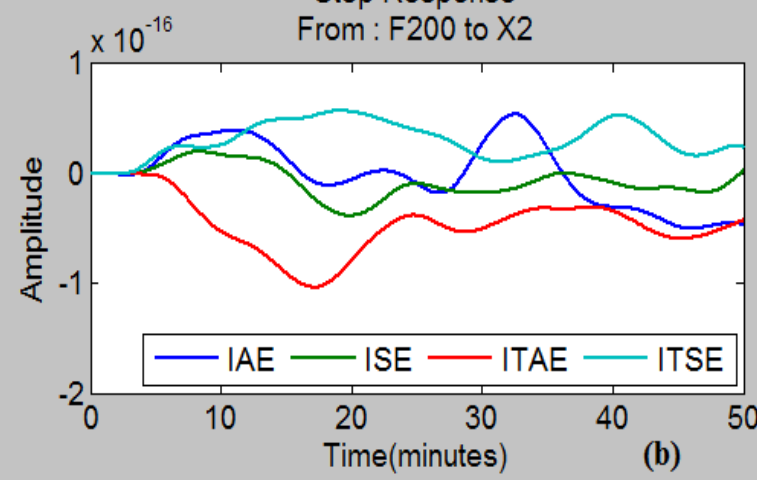

Step Response

From : F200 to P2

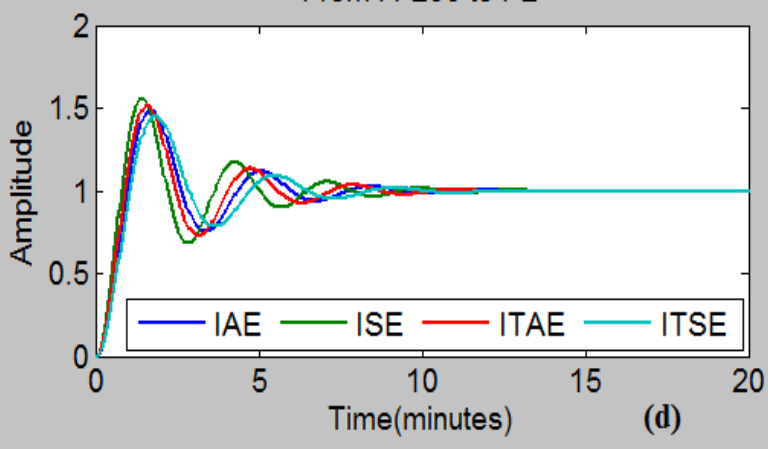

Fig. 5a Unit-Step response of proposed decoupler controllers using GA using first group

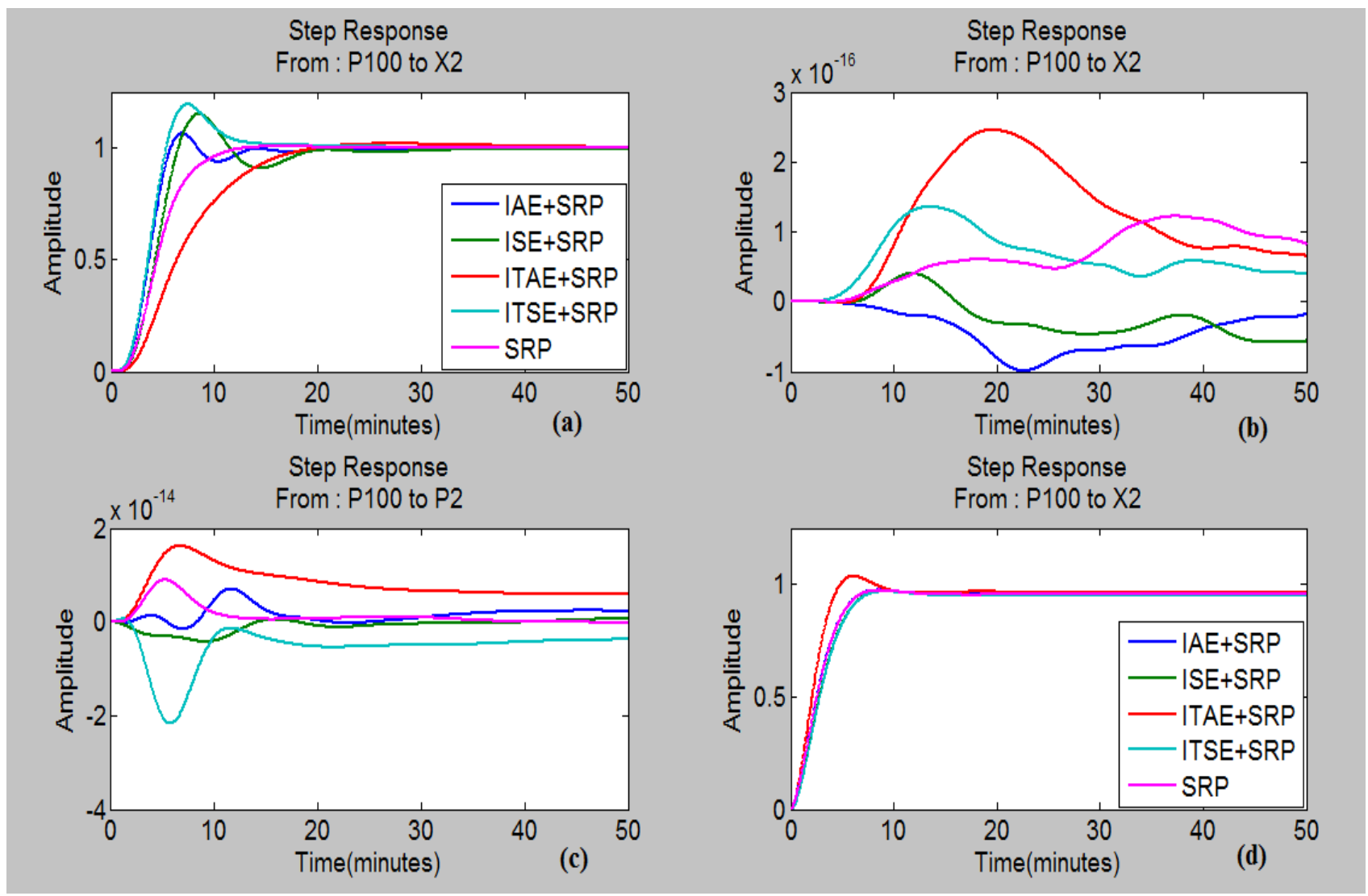

Fig. 5b Unit-Step response of proposed decoupler controllers using GA using second group and SRP cost function 


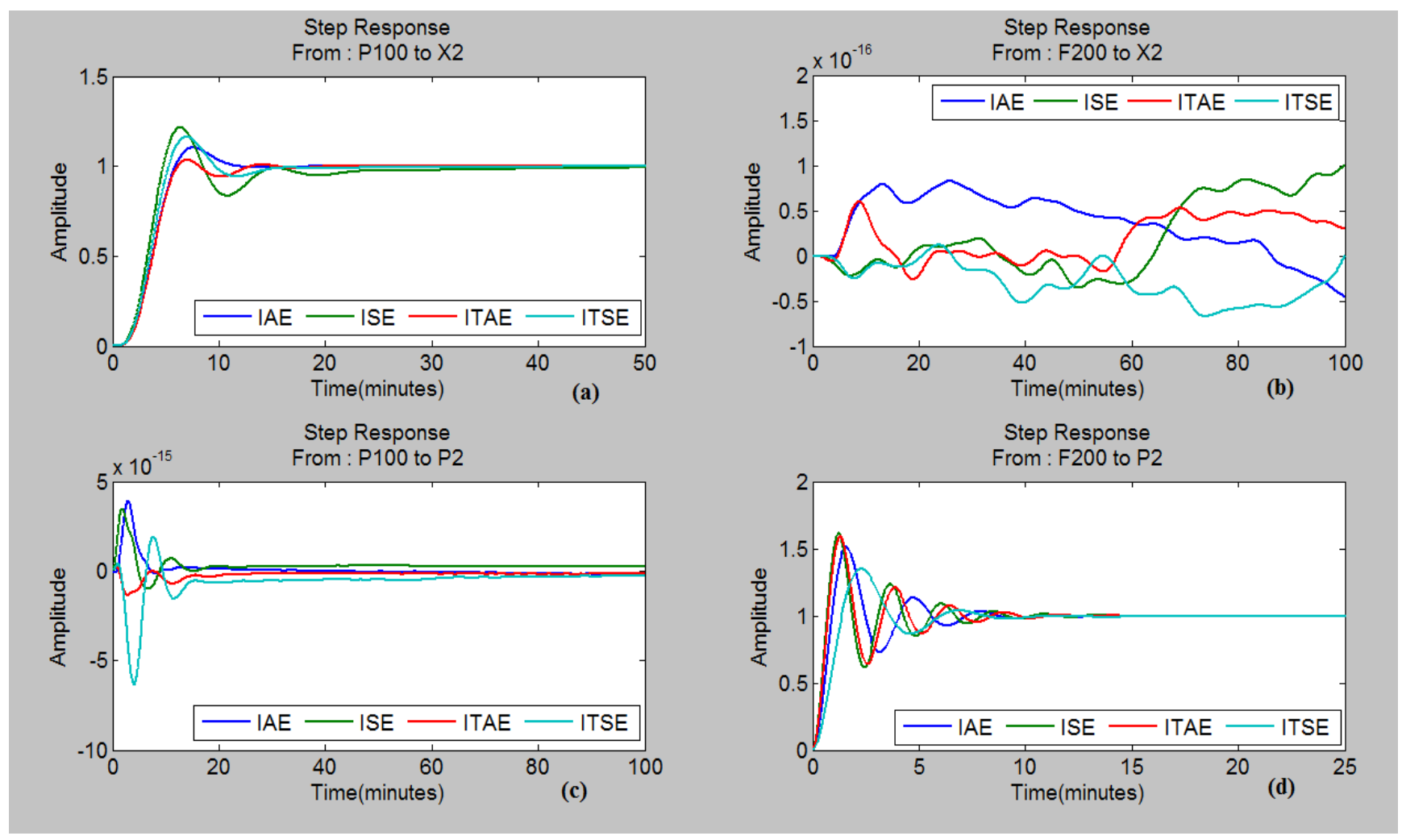

Fig. 6a Unit-Step response of proposed decoupler controllers using PSO using first group

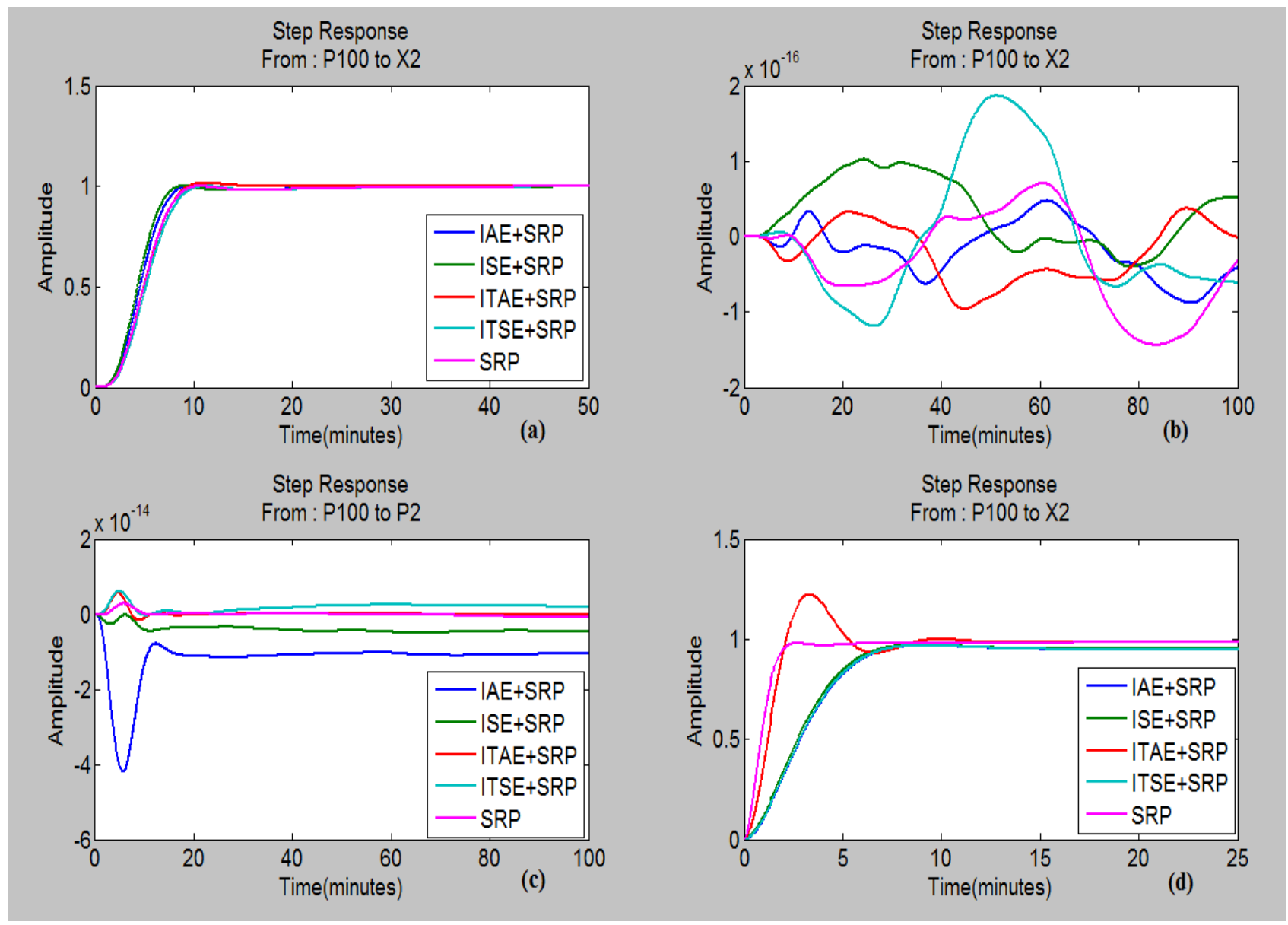

Fig. 6bUnit-Step response of proposed decoupler controllers using PSO using second group and SRP cost function 
Table 8 Parameters of proposed controllers $C_{1}$ using GA with two groups of cost functions and SRP cost function, also summation of step response parameters (SRP values), their gain margin (GM) and phase margin (PM) to step change in disturbance variable F1 of $30 \%$ decrease (the dashed row indicates its best in SRP or Stability)

\begin{tabular}{|c|c|c|c|c|c|c|c|}
\hline $\begin{array}{l}\text { First } \\
\text { group }\end{array}$ & SRP & $\begin{array}{l}\text { GM } \\
\text { (dB) }\end{array}$ & $\begin{array}{l}\text { PM } \\
(\text { deg) }\end{array}$ & $\begin{array}{l}\text { Second } \\
\text { group +SRP }\end{array}$ & SRP & $\begin{array}{l}\text { GM } \\
\text { (dB) }\end{array}$ & $\begin{array}{l}\text { PM } \\
\text { (deg) }\end{array}$ \\
\hline IAE & 32.8003 & 2.045 & 56.929 & IAE+SRP & 19.351 & 2.4108 & 65.3154 \\
\hline ISE & 55.6497 & 1.7823 & 43.2506 & ISE+SRP & 35.5014 & 2.3859 & 58.2211 \\
\hline ITAE & 30.0952 & 2.0554 & 63.2282 & ITAE+SRP & 45.5589 & 5.981 & 70.0976 \\
\hline ITSE & 52.1825 & 1.8195 & 45.0237 & ITSE+SRP & 35.979 & 2.5735 & 52.6668 \\
\hline & & & & SRP & 18.5872 & 4.0292 & 68.0896 \\
\hline
\end{tabular}

Table 9 Parameters of proposed controllers $C_{1}$ using PSO with two groups of cost functions and SRP cost function, also summation of step response parameters (SRP values), their gain margin (GM) and phase margin (PM) to step change in disturbance variable $\mathrm{F} 1$ of $30 \%$ decrease (the dashed row indicates its best in SRP or Stability)

\begin{tabular}{|c|l|l|l|l|l|l|l|}
\hline $\begin{array}{c}\text { First } \\
\text { group }\end{array}$ & SRP & $\begin{array}{l}\text { GM } \\
(\mathrm{dB})\end{array}$ & $\begin{array}{l}\text { PM } \\
(\mathrm{deg})\end{array}$ & $\begin{array}{l}\text { Second } \\
\text { group } \\
\text { +SRP }\end{array}$ & SRP & $\begin{array}{l}\text { GM } \\
(\mathrm{dB})\end{array}$ & $\begin{array}{l}\text { PM } \\
(\mathrm{deg})\end{array}$ \\
\hline IAE & $\mathbf{2 2 . 4 0 8 2}$ & $\mathbf{2 . 7 2 9 3}$ & $\mathbf{5 9 . 4 1 8 3}$ & IAE+SRP & $\mathbf{1 4 . 2 1 1 4}$ & $\mathbf{3 . 2 5 1}$ & $\mathbf{6 6 . 5 0 9 5}$ \\
\hline ISE & $\mathbf{5 2 . 3 5 0 6}$ & 2.0067 & 54.5188 & ISE+SRP & 13.3474 & 3.1805 & $\mathbf{6 6 . 3 6 2 9}$ \\
\hline ITAE & $\mathbf{1 6 . 1 8 3 8}$ & $\mathbf{2 . 4 6 1 1}$ & $\mathbf{6 6 . 8 5 1 6}$ & ITAE+SRP & $\mathbf{1 6 . 5 0 4 6}$ & $\mathbf{3 . 4 1 5 1}$ & $\mathbf{6 4 . 8 1 5 9}$ \\
\hline ITSE & $\mathbf{3 0 . 8 2 2 6}$ & $\mathbf{2 . 3 4 3 9}$ & 57.1797 & ITSE+SRP & $\mathbf{1 6 . 2 2 4}$ & $\mathbf{3 . 3 8 7}$ & $\mathbf{6 6 . 7 2 2 3}$ \\
\hline
\end{tabular}

Table 10 Parameters of proposed controllers $C_{2}$ using GA with two groups of cost functions and SRP cost function, also summation of step response parameters (SRP values), their gain margin (GM) and phase margin (PM) to step change in disturbance variable F1 of $30 \%$ decrease (the dashed row indicates its best in SRP or Stability)

\begin{tabular}{|c|c|c|c|c|c|c|c|}
\hline $\begin{array}{c}\text { First } \\
\text { group }\end{array}$ & SRP & $\begin{array}{l}\text { GM } \\
\text { (dB) }\end{array}$ & $\begin{array}{c}\text { PM } \\
\text { (deg) }\end{array}$ & $\begin{array}{l}\text { Second } \\
\text { group } \\
+ \text { SRP }\end{array}$ & SRP & $\begin{array}{l}\text { GM } \\
\text { (dB) }\end{array}$ & $\begin{array}{c}\text { PM } \\
(\text { deg) }\end{array}$ \\
\hline IAE & 58.4991 & 62.5228 & 24.7556 & IAE+SRP & 15.3988 & Inf & 72.9687 \\
\hline ISE & 65.2869 & 24.8395 & 20.5312 & ISE+SRP & 16.0629 & Inf & 72.5347 \\
\hline ITAE & 60.7945 & 59.0179 & 23.2332 & ITAE+SRP & 19.1347 & Inf & 64.1396 \\
\hline ITSE & 55.5382 & 612.3213 & 26.9884 & ITSE+SRP & 16.2859 & Inf & 72.3856 \\
\hline & & & & SRP & 15.411 & Inf & 72.9928 \\
\hline
\end{tabular}

Table 11 Parameters of proposed controllers $C_{2}$ using PSO with two groups of cost functions and SRP cost function, also summation of step response parameters (SRP values), their gain margin (GM) and phase margin (PM) to step change in disturbance variable F1 of $30 \%$ decrease (the dashed row indicates its best in SRP or Stability)

\begin{tabular}{|c|l|l|l|l|l|l|l|}
\hline $\begin{array}{c}\text { First } \\
\text { group }\end{array}$ & SRP & $\begin{array}{l}\text { GM } \\
(\mathrm{dB})\end{array}$ & $\begin{array}{l}\text { PM } \\
(\mathrm{deg})\end{array}$ & $\begin{array}{l}\text { Second } \\
\text { group } \\
\text { +SRP }\end{array}$ & SRP & $\begin{array}{l}\text { GM } \\
(\mathrm{dB})\end{array}$ & $\begin{array}{l}\text { PM } \\
(\mathrm{deg})\end{array}$ \\
\hline IAE & $\mathbf{6 0 . 5 1 1}$ & $\mathbf{7 6 . 5 1 8 3}$ & $\mathbf{2 3 . 3 0 3 5}$ & IAE+SRP & $\mathbf{1 6 . 2 9 4 7}$ & inf & $\mathbf{7 2 . 3 7 3 7}$ \\
\hline ISE & $\mathbf{7 2 . 1 7 9 2}$ & $\mathbf{1 4 . 5 6 6 2}$ & $\mathbf{1 7 . 1 3 0 2}$ & ISE+SRP & $\mathbf{1 5 . 8 7 4 4}$ & inf & $\mathbf{7 2 . 6 7 7 1}$ \\
\hline ITAE & $\mathbf{6 8 . 1 3 7 5}$ & $\mathbf{1 7 . 8 9 6 7}$ & $\mathbf{1 8 . 3 6 3 1}$ & ITAE+SRP & $\mathbf{1 9 . 1 7 4 3}$ & inf & $\mathbf{4 5 . 0 9 7 5}$ \\
\hline ITSE & $\mathbf{4 4 . 5 6 3 2}$ & inf & $\mathbf{3 4 . 6 3 4}$ & ITSE+SRP & $\mathbf{1 6 . 2 0 5 9}$ & inf & $\mathbf{7 2 . 4 3 7 4}$ \\
\hline
\end{tabular}

